Mineralogical Journal, Vol. 6, No. 6, pp. 464-476, ApriL"1972

\title{
SYNTHETIC Mg-CHLORITE IN RELATION TO NATURAL CHLORITE
}

\author{
HARUO SHIROZU and HITOSHI MOMOI \\ Department of Geology, Kyushu University, Fukuoka, Japan
}

\begin{abstract}
$\mathrm{X}$-ray and infrared studies have been made on synthetic materials prepared hydrothermally at $300-660^{\circ} \mathrm{C}$ and $18,000-38,000$ psi from gels with compositions ranging from pennine to amesite. The results indicate that the solid solution range of the chlorite phase does not extend to the amesite composition in the present experimental conditions; the range is almost identical or slightly extended to the Al-rich side compared with that of natural well-crystallized Mg-chlorites. The polytype of the synthetic $\mathrm{Mg}$ chlorite is II $b$, which exhibits regular stacking in the high aluminum materials. The differences in cell dimensions and $O H$ bands between the synthetic and natural chlorites suggest a difference in the distribution of cations within the talc and brucite octahedral layers. An even distribution of the octahedral cations is inferred for the synthetic chlorite, which is regarded as a high temperature form. The latter conclusion is supported by a hydrothermal treatment of natural chlorite. Additional information on the polytypes of the serpentine phase is also presented.
\end{abstract}

\section{Introduction}

Since Yoder (1952) synthesized clinochlore, $\mathrm{Mg}_{5} \mathrm{Al}\left(\mathrm{Si}_{3} \mathrm{Al}\right)_{10}(\mathrm{OH})_{8}$, in the study of the system $\mathrm{MgO}-\mathrm{Al}_{2} \mathrm{O}_{3}-\mathrm{SiO}_{2}-\mathrm{H}_{2} \mathrm{O}$, hydrothermal investigations concerning the chlorite $(14 \AA)$ and serpentine $(7 \AA)$ phases were made by Roy and Roy (1955), Nelson and Roy (1958), Gillery (1959), Segnit (1963), and Fawcett and Yoder (1966). Nelson and Roy, and Gillery demonstrated in their studies that the solid solution of the chlorite phase extended from near serpentine, $\mathrm{Mg}_{6} \mathrm{Si}_{4} \mathrm{O}_{10}(\mathrm{OH})_{8}$ * to amesite, $\mathrm{Mg}_{4} \mathrm{Al}_{2}\left(\mathrm{Si}_{2} \mathrm{Al}_{2}\right) \mathrm{O}_{10}(\mathrm{OH})_{8}$, and also that the cell dimensions. 
of the synthetic chlorites were different from those of the corresponding natural chlorites. On the other hand, in the course of study of natural chlorites by one of us, it was revealed that the solid solution range of the chlorites was rather narrow, at least in the well-crystallized trioctahedral series (Shirozu, 1960). We were interested primarily in these discrepancies between the synthetic and natural chlorites, and made some $\mathrm{X}$-ray and infrared studies of synthetic materials prepared hydrothermally.

This paper discusses the solid solution range and mineralogical properties of the synthetic $\mathrm{Mg}$-chlorites in comparison with those of the natural chlorites, and it is indicated that the synthetic chlorite may be regarded as a high temperature form of chlorite. In addition, some data are presented for the serpentine phases which were obtained as precursors to chlorite in the syntheses.

\section{Experimental}

The starting materials were prepared in the form of amorphous gels of alumina, magnesia, and silica by the procedure (silica-nitrate method) described by Roy (1956). Their compositions correspond to the formula

$$
\left(\mathrm{Mg}_{B-x} \mathrm{Al}_{x}\right)\left(\mathrm{Si}_{4-x} \mathrm{Al}\right) \mathrm{O}_{10}(\mathrm{OH})_{8}
$$

with $x$ values of $0.50,0.75,1.00,1.25,1.50,1.75$, and 2.00 for the chlorites produced if complete reaction takes place.

The temperature was between $300^{\circ}$ and $660^{\circ} \mathrm{C}$, hydrothermal pressure between 18,000 and 38,000 psi, and duration from 5 to 31 days. The conditions of the main runs are shown in Table 1 . The gels were subjected to reaction in sealed silver capsules in test-tube bombs.

The treated specimens were examined by means of an X-ray diffractometer using $\mathrm{Cu} K \alpha$ radiation. The $d(001)$ and $b_{0}$ parameters of serpentine and chlorite were calculated from $00 l$ and 060 spacings, 
Table 1. Data of main hydrothermal runs.

\begin{tabular}{|c|c|c|c|c|c|c|}
\hline $\begin{array}{c}\text { Comp. } \\
x\end{array}$ & $\begin{array}{l}\text { Temp. } \\
{ }^{\circ} \mathrm{C}\end{array}$ & $\begin{array}{c}\text { Pressure } \\
\text { psi }\end{array}$ & $\begin{array}{c}\text { Duration } \\
\text { days }\end{array}$ & Phases & $d \underset{\AA}{d(001)}$ & $\begin{array}{l}b \\
\AA\end{array}$ \\
\hline \multirow[t]{3}{*}{0.50} & 300 & 17,500 & 20 & Serp & 7.22 & 9.25 \\
\hline & 620 & 30,000 & 20 & $\begin{array}{l}\text { Chl }+ \text { For }+ \text { Talc } \\
55: 30: 15\end{array}$ & 14.34 & 9.22 \\
\hline & 660 & 30,000 & 5 & Chl + Serp + For $+1 . T$ & ralc & \\
\hline \multirow[t]{2}{*}{0.75} & 600 & 37,000 & 22 & $\mathrm{Chl}+1$. For & & \\
\hline & 615 & 38,000 & 31 & $\begin{array}{l}\text { Chl }+ \text { For } \\
90: 10\end{array}$ & 14.31 & 9.22 \\
\hline \multirow[t]{4}{*}{1.00} & 400 & 18,000 & 20 & Serp. & 7. 16 & 9.21 \\
\hline & 600 & 35,000 & 20 & Chl & 14.30 & 9.215 \\
\hline & 630 & 30,000 & 20 & $\mathrm{Chl}$ & & \\
\hline & 660 & 30,000 & 5 & $\mathrm{Chl}+1$. Serp +1 . For & & \\
\hline \multirow[t]{2}{*}{1.25} & 600 & 37,000 & 22 & Chl+1. Serp & & \\
\hline & 615 & 38,000 & 31 & $\mathrm{Chl}$ & 14.25 & 9.21 \\
\hline \multirow[t]{4}{*}{1.50} & 400 & 18,000 & 20 & Serp & 7. 10 & 9. 19 \\
\hline & 600 & 35,000 & 20 & Chl + tr. Serp & 14. 21 & 9.20 \\
\hline & 630 & 35,000 & 19 & $\mathrm{Chl}+$ tr. Serp & & \\
\hline & 650 & 20,000 & 7 & Chl +1. Serp & & \\
\hline \multirow[t]{4}{*}{1.75} & 400 & 18,000 & 20 & Serp & 7.08 & 9.17 \\
\hline & 590 & 35,000 & 20 & Serp +tr. Chl & 7.08 & 9.18 \\
\hline & 620 & 30,000 & 20 & $\begin{array}{l}\text { Chl }+ \text { Serp }+ \text { Spinel } \\
85: 7: 8\end{array}$ & 14.20 & 9.20 \\
\hline & 650 & 20,000 & 7 & $\mathrm{Chl}+\operatorname{Serp}+1$. Spinel & & \\
\hline \multirow[t]{4}{*}{2.00} & 400 & 18,000 & 20 & Serp & 7.04 & 9.16 \\
\hline & 590 & 35,000 & 20 & Serp +tr. Chl & 7.04 & 9.17 \\
\hline & 630 & 30,000 & 20 & $\begin{array}{l}\text { Chl }+ \text { Serp }+ \text { Spinel } \\
70: 10: 20\end{array}$ & 14. 19 & 9.19 \\
\hline & 650 & 20,000 & 7 & $\mathrm{Chl}+$ Serp + Spinel & & \\
\hline
\end{tabular}

Chl, chlorite; Serp, serpentine; For, forsterite; 1., little; tr., trace.

respectively, which were calibrated by an internal standard of silicon.

The infrared absorption spectra were recorded with the Hitachi Model EPI-G grating infrared spectrophotometer. The $\mathrm{KBr}$ pellet technique was used.

In addition to the synthetic experiments, a natural chlorite was treated hydrothermally and examined. 
Phases and polytypes produced

The results of the $\mathrm{X}$-ray examination of the treated specimens. agree generally with those of the previous studies except for some detailed points. The serpentine structure was produced readily at

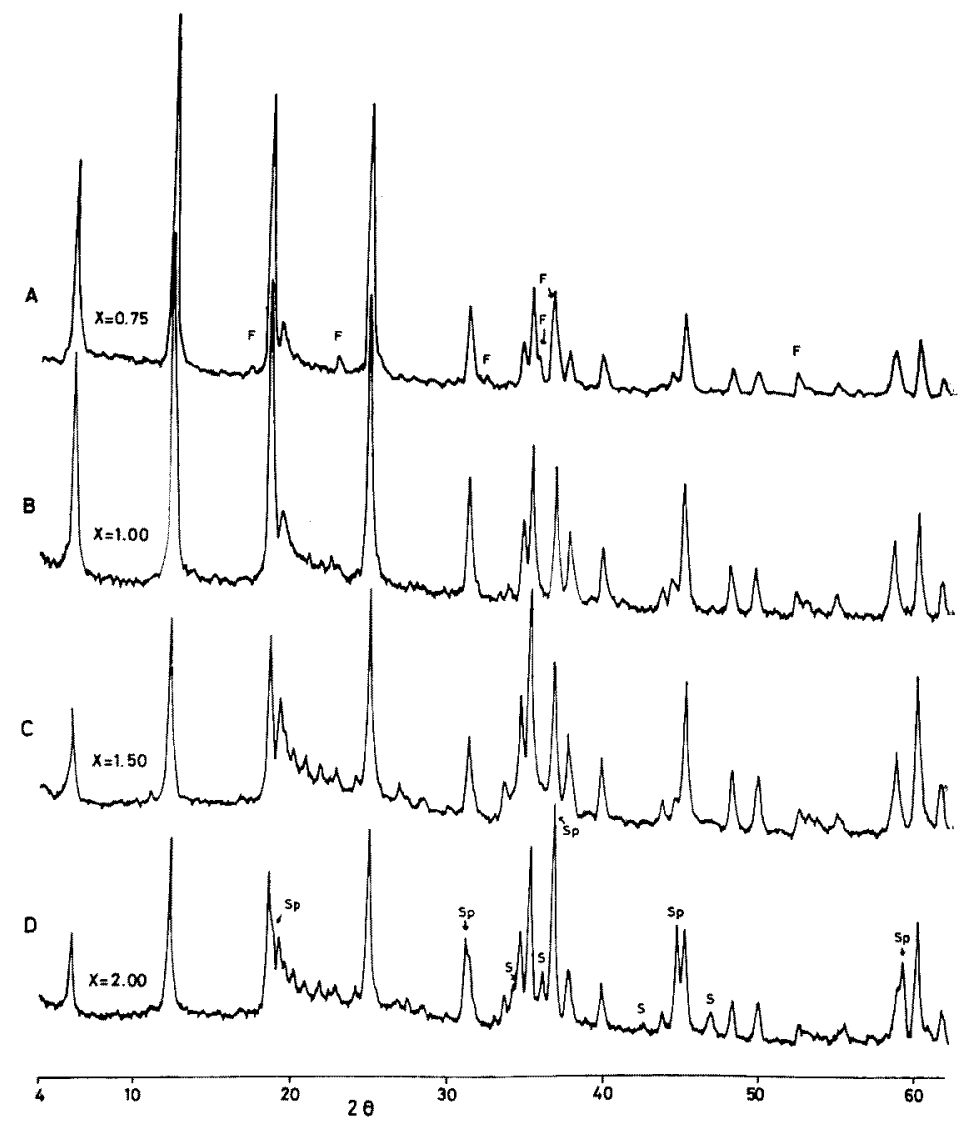

Fig. 1. X-ray powder patterns of synthetic Mg-chlorites prepared under conditions: A. $615^{\circ} \mathrm{C}, 38,000 \mathrm{psi}, 31$ days from composition with $x=0.75$. B. $600^{\circ} \mathrm{C}, 35,000 \mathrm{psi}, 20$ days from composition with $x=1.00$. C. $630^{\circ} \mathrm{C}, 35,000 \mathrm{psi}, 19$ days from composition with $x=1.50$. D. $630^{\circ} \mathrm{C}$, 30,000 psi, 20 days from composition with $x=2.00$. F, forsterite. $\mathrm{Sp}$. spinel. $S$, serpentine phase. 
relatively low temperatures for every composition, and the chlorite structure formed slowly from the serpentine phases at higher temperatures. Pure or almost pure chlorite phases were obtained only from the intermediate compositions with $x$ values of $1.00,1.25$, and 1.50, whereas the low and high aluminum compositions produced mixed phases with talc, forsterite, and/or spinel, depending on the initial gel compositions, as presented in Table 1 and Fig. 1. For some products approximate ratios of the phases were estimated (Table 1 ) by comparing their $\mathrm{X}$-ray patterns with those of artificial mixtures. The results indicate that the compositions of chlorites produced in low and high aluminum materials have been changed from the starting compositions, suggesting a rather narrow solid solution range.

The polytype of chlorites produced in all compositions was the Ilb type of Bailey and Brown (1962), which is the common form in natural $\mathrm{Mg}$-chlorites. In the high aluminum materials $(x \geqq 1.25)$, existence of a regular layer stacking was indicated by a series of additional weak $k \neq 3 n$ reflections with $02 l, 11 l$, and $11 l$ indices, which were observed from about $20^{\circ}$ to $30^{\circ}$ in $2 \theta$ (Fig. 1C, D). The 02 tailed band, indicating random stacking, was also associated with the $k \neq 3 n$ reflections. Very similar $k \neq 3 n$ reflections are known in the powder pattern of a natural dioctahedral chlorite (Eggleton \& Bailey, 1967), but are not common in natural Mg-chlorites.

The polytypes of the synthetic serpentine phase were shown to depend mainly upon the composition by Gillery (1959), who recognized 1-layer ortho-serpentine in the low aluminum and a 6(3)-layer ortho variety in the high aluminum compositions. These polytypes were discussed by Bailey and Tyler (1960). In the present investigation, a 1-layer polytype was produced in the low aluminum compositions similarly to the results of Gillery. In the high aluminum compositions, however, not only the 6(3)-layer type but also the 6(2)layer type was found (Fig. 2). The former structure was produced 


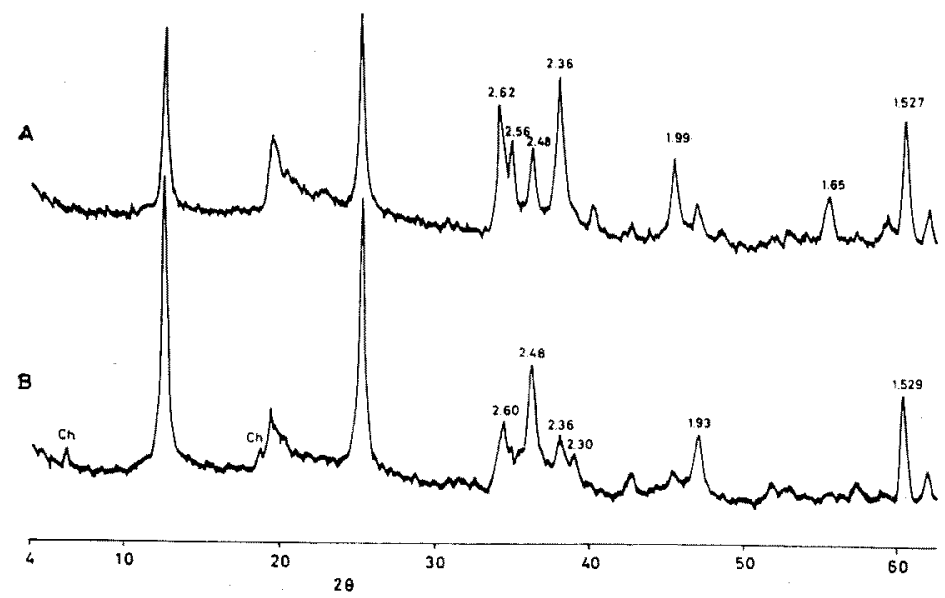

Fig. 2. X-ray powder patterns of synthetic aluminian serpentines (amesites). A. 6(3)-layer type with a small amount of 6(2)-layer type: $400^{\circ} \mathrm{C}, 18,000 \mathrm{psi}, 20$ days from composition with $x=2.00$. B. $6(2)$-layer type with a small amount of $6(3)$-layer type: $590^{\circ} \mathrm{C}, 35,000 \mathrm{psi}, 20$ days from composition with $x=2.00$. Ch, chlorite.

at relatively low temperatures $\left(300-400^{\circ} \mathrm{C}\right)$ and is correlated with the 1M-3T structures of Bailey (1969); the latter structure was produced at high temperatures $\left(600^{\circ} \mathrm{C}\right)$ and is correlated with group $\mathrm{D}$ of Bailey. The patterns of the latter therefore are similar to that of natural amesite, which usually crystallizes as the $2 \mathrm{H}_{2}$ polytype within group D.

\section{Cell dimensions}

The values of the cell dimensions, $d(001)$ and $b_{0}$, of both the chlorite and serpentine phases show a progressive decrease with increasing $x$ (Table 1). This general relation is in agreement 'with those of the previous studies, but there are some differences in detail. The $d(001)$ parameter versus composition curve of chlorite obtained here is shown in Fig. 3, in which some previous curves for the synthetic and natural trioctahedral chlorites are also given for comparison. 


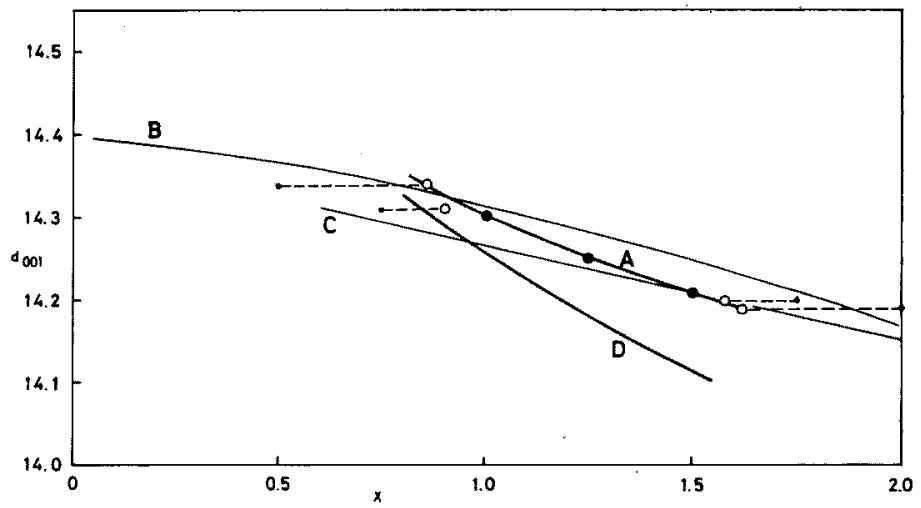

Fig. 3. Variation of basal spacing of synthetic and natural chlorites with composition. A, B and C, curves for synthetic Mg-chlorites. A, this paper; B, Nelson and Roy (1958); C, Gillery (1959). D, curve for natural trioctahedral chlorites (Shirozu, 1958).

The present curve ( $\mathrm{A}$ in Fig. 3) is drawn taking account of the changes of compositions of the chlorites from the starting compositions as mentioned already. The black circles are plotted for the pure chlorite phases. The open circles are for the inferred resultant compositions of chlorite, which are obtained by subtraction of the coexisting phases and jointed by dashed lines to the dot marks showing starting composition.

It is confirmed that synthetic chlorites have larger basal spacings than the corresponding natural chlorites. The difference is greater in the high aluminum portion, but the reliable curves for the synthetic and natural chlorites ( $A$ and $D$ in Fig. 3) are mutually subparallel even in the low aluminum portion.

\section{Infrared patterns}

The infrared absorption spectra of the chlorites and of the Alrich serpentines are shown in Figs. 4 and 5 respectively.. The three middle patterns $B, C$, and D in Fig. 4 are of pure chlorite. The 

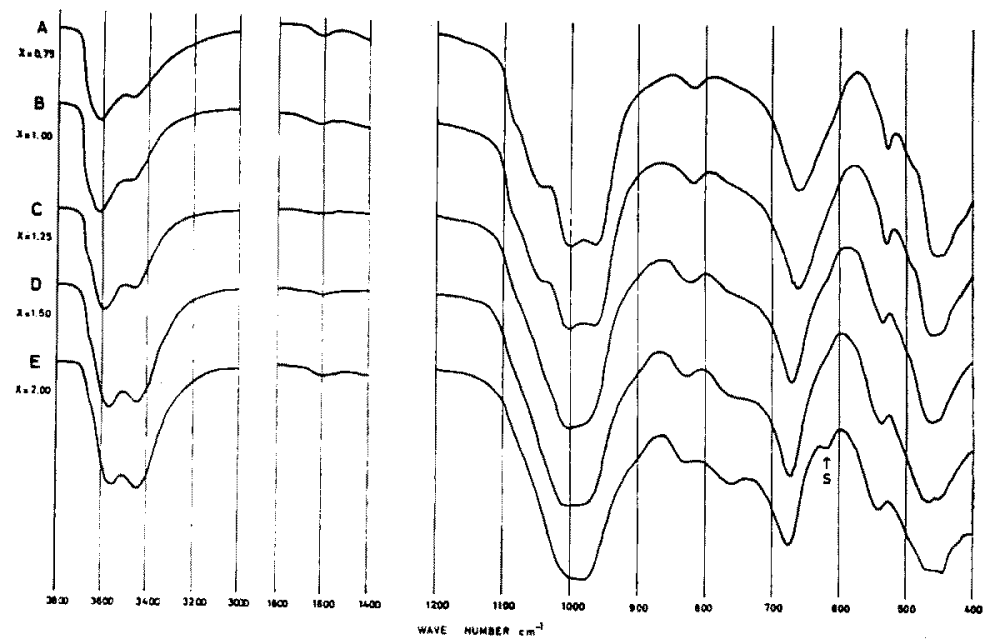

Fig. 4. Infrared absorption spectra of synthetic $\mathrm{Mg}$-chlorites prepared under conditions : A. $615^{\circ} \mathrm{C}, 38,000$ psi, 31 days from composition with $x=0.75$. B. $600^{\circ} \mathrm{C}, 35,000$ psi, 20 days from composition with $x=1.00$. C. $615^{\circ} \mathrm{C}, 38,000 \mathrm{psi}, 31$ days from composition with $x=1.25$. D. $630^{\circ} \mathrm{C}$, 35,000 psi, 19 days from composition with $x=1.50$. E. $630^{\circ} \mathrm{C}, 30,000$ psi, 20 days from composition with $x=2.00$. S, band due to serpentine phase.

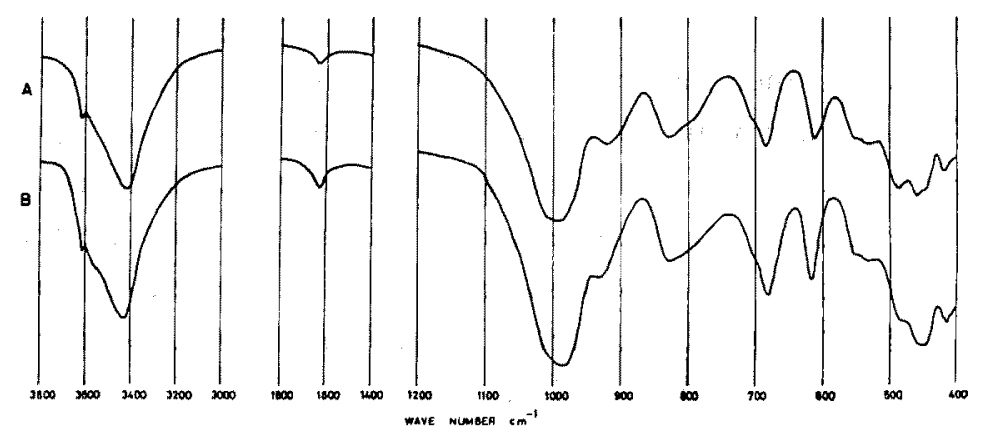

Fig. 5. Infrared absorption spectra of synthetic aluminian serpentines (amesites). A. 6(3)-layer type: $400^{\circ} \mathrm{C}, 18,000 \mathrm{psi}, 20$ days from composition with $x=2.00$. B. $6(2)$-layer type $: 590^{\circ} \mathrm{C}, 35,000$ psi, 20 days from composition with $x=2.00$. 
patterns $A$ and $E$ contain some impurities, the effect of which is recognized only in pattern $E$ : the weak band at $620 \mathrm{~cm}^{-1}$ is due to a serpentine phase (refer to Fig. 5). The similarity of the patterns between $\mathrm{A}(x=0.75)$ and $\mathrm{B}(1.00)$ and between $\mathrm{D}(1.50)$ and $\mathrm{E}(2.00)$ suggests that the chemical compositions of the chlorite phases comprising each pair are very similar.

There are close relations between the infrared patterns and chemical compositions. In the lattice vibration region, the main $\mathrm{Si}-\mathrm{O}$ bands in the frequency region between 950 and $1100 \mathrm{~cm}^{-1}$ and the strong band between 660 and $680 \mathrm{~cm}^{-1}$ show the most significant change with chemical composition. The variation of the former bands was noticed previously in natural chlorites (Tuddenham \& Lyon, 1959), and of the latter bands in synthetic (Stubican \& Roy, 1961) and natural chlorites (Hayashi \& Oinuma, 1965).

In the hydroxyl-stretching region, with increasing aluminum content the two broad $\mathrm{OH}$ bands between 3400 and $3650 \mathrm{~cm}^{-1}$, which are attributed to the brucite $\mathrm{OH}$ by Serratosa \& Vinas (1964), shift in the direction of lower frequencies, and simultaneously the relative intensity of the band with lower frequency increases. These relations are quite similar to those of the natural trioctahedral chlorites (Shirozu, 1967). The vibration frequencies of the synthetic chlorites, however, are higher than those of the corresponding natural $\mathrm{Mg}$ chlorites, as shown in Fig. 6a. It may indicate longer hydrogen bond distances of the synthetic chlorites between the basal tetrahedral oxygens and the brucite hydroxyls. It is noticeable that the intensity ratios of the two bands are almost identical in both the synthetic and natural $\mathrm{Mg}$-chlorites (Fig. 6b): the relative intensities of the $\mathrm{OH}$ bands can be correlated with the aluminum contents in the tetrahedral layers. It may also be noteworthy that there is no distinct band at about $3670-3680 \mathrm{~cm}^{-1}$, at which a small band assigned to the talc $\mathrm{OH}$ appears generally in the spectra of natural $\mathrm{Mg}$-chlorites. This difference may suggest a difference in the talc octahedral 

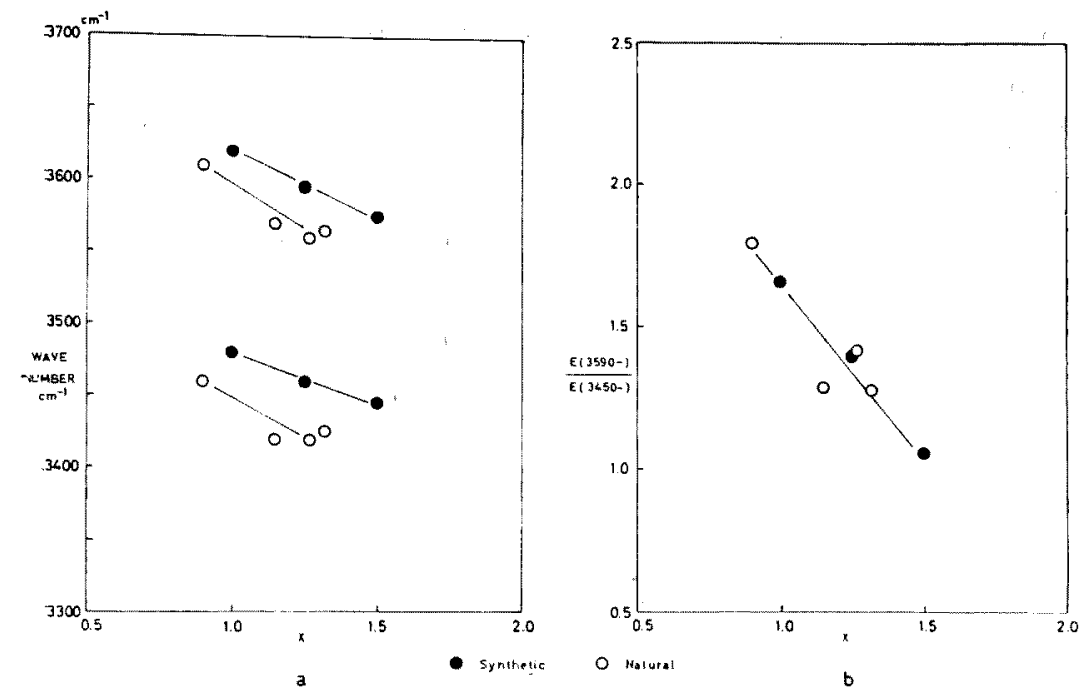

Fig. 6. Variation of two broad OH bands between 3400 and $3650 \mathrm{~cm}^{-1}$ of synthetic and natural $\mathrm{Mg}$-chlorites with composition. Black circle, synthetic; open circle, natural. a. Variation of vibration frequency. b. Variation of intensity ratio.

cations between the synthetic and natural Mg-chlorites, e.g. that the former contains some aluminum ions in the talc octahedral layer, but the latter does not.

\section{Discussion, and an additional experiment}

In contrast to earlier studies, the experimental data described above indicate that the solid solution range of the chlorite phase is rather narrow and does not extend to the amesite composition in the present experimental conditions of relatively low pressures. The $x$ values of the chlorite formula take a range presumably from about 0.8 to 1.6 at about $2 \mathrm{~kb}$ pressure. This range is almost identical or slightly extended to the Al-rich side compared with that $(x=0.8-1.4)$ of the natural well-crystallized $\mathrm{Mg}$-chlorites (Shirozu, 1960).

Recent hydrothermal data at pressures up to $10 \mathrm{~kb}$ by Fawcett 
and Yoder (1966) show that the composition of chlorite at maximum thermal stability becomes more aluminous at high pressures. The solid solution range also may vary with pressure. Segnit (1963) reports that a mixed phase of chlorite and serpentine formed from. the amesite composition at pressures up to $30 \mathrm{~kb}$. This chloritemight have a composition somewhat close to amesite.

The differences in the basal spacings and $\mathrm{OH}$ bands between: the synthetic and natural chlorites can be explained by a difference: in distribution of octahedral cations betweent the talc and brucite. layers, as discussed by Gillery (1959), who inferred an uneven. distribution (more aluminous in the talc octahedral layer) for the synthetic chlorite. The recent structural studies of natural chlorites, however, indicate that the octahedral aluminum is concentrated in. the brucite layer (see Bailey, 1966), and for the present an even: distribution for the synthetic chlorite may be more plausible. The infrared data presented above also support this deduction together with the fact that the chlorite phases are formed by way of serpentine phases. Thus the structural formula for the synthetic: $\mathrm{Mg}$-chlorite may be written as follows:

$$
\left[\mathrm{Mg}_{3-x / 2} \mathrm{Al}_{x / 2}(\mathrm{OH})_{6}\right]^{x / 2+}\left[\left(\mathrm{Mg}_{3-x / 2} \mathrm{Al}_{x / 2}\right)\left(\mathrm{Si}_{4-x} \mathrm{Al}_{x}\right) \mathrm{O}_{10}(\mathrm{OH})_{2}\right]^{x / 2-}
$$

The formula for the natural trioctahedral $\mathrm{Mg}$-chlorite (orthochlorite) is :

$$
\left[\mathrm{Mg}_{8-x} \mathrm{Al}_{x}(\mathrm{OH})_{6}\right]^{x+}\left[\mathrm{Mg}_{3}\left(\mathrm{Si}_{4-x} \mathrm{Al}_{x}\right) \mathrm{O}_{10}(\mathrm{OH})_{2}\right]^{x-} \text {. }
$$

The difference in distribution of cations within the two octahedral layers implies a difference interlayer charges and bonding forces, which are believed to be necessary to hold together the chlorite structure, an alternation of talc-like and brucite-like layers. Therefore, some discrepancy in the solution range as presented above: is reasonable between synthetic and natural chlorites.

It is an important fact that the synthetic and natural chlorites. are different in detailed properties. These two types of chlorite 
may be regarded as dimorphous. In this respect, the synthetic chlorite may be a high temperature form because of its lower density and the probable disordering of octahedral cations between the two octahedral layers as well as its relatively high temperature of formation.

In order to confirm this interpretation, a natural Mg-chlorite was treated hydrothermally (at $615^{\circ} \mathrm{C}, 38,000$ psi, 20 days). Its chemical composition corresponded to $x=1.27$. As given in Table 2, by the treatment its $\mathrm{X}$-ray and infrared patterns have undergone slight changes toward those of the synthetic chlorite with the corresponding composition, indicating that a transformation or a recrystallization to the synthetic-type structure has occurred.

Table 2. Changes of the basal spacing and $\mathrm{OH}$ bands by hydrothermal treatment for $\mathrm{Mg}$-chlorite from Muramatsu, Nagasaki Prefecture.

\begin{tabular}{lcccc}
\hline & $d(001)$ & \multicolumn{3}{c}{$\mathrm{OH}$ bands } \\
\cline { 3 - 5 } & $\AA$ & $\mathrm{cm}^{-1}$ & $\mathrm{~cm}^{-1}$ & $\mathrm{~cm}^{-1}$ \\
\hline Untreated & 14.18 & 3675 & 3560 & 3420 \\
Treated & 14.21 & - & 3570 & 3435 \\
\hline
\end{tabular}

Chemical formula (Shirozu, 1958):

$$
\left(\mathrm{Mg}_{4 . ; 36} \mathrm{Mn}_{0.054} \mathrm{Fe}_{0.074}^{3+} \mathrm{Al}_{1.155}\right)\left(\mathrm{Si}_{2.730} \mathrm{Al}_{1.270}\right) \mathrm{O}_{10}(\mathrm{OH})_{8}
$$

Hydrothermal conditions : $615^{\circ} \mathrm{C}, 38,000$ psi, 20 days.

Thus the synthetic chlorite is considered to be the high temperature phase, which might be found in nature in rocks metamorphosed thermally or formed at high temperatures such as skarn. There is, however, no definite evidence for the occurrence in nature of chlorites similar to the synthetic-type so far. On the other hand, the natural well-crystallized trioctahedral chlorite may be regarded as a low temperature (and high pressure) phase, which has not yet been synthesized hydrothermally. Its stability field may overlap the field of the serpentine phase, which may be metastable. It is also possible that there exists an intermediate structure between the 
"synthetic-type" and "natural-type" because they are in the relation of an order-disorder type of polymorphism. These points are future problems of interest.

\section{Acknowledgments}

Part of our synthetic experiments was made in the laboratory of Professor M. Koizumi of the Institute of Scientific and Industrial Research, Osaka University, to whom we wish to acknowledge our indebtedness. Hearty thanks are due also to Mr. T. Harada of our laboratory for his assistance in the experimental work. We are greatly indebted to Professor S. W. Bailey of University of Wisconsin, who supplied $X$-ray data on serpentine polytypes and reviewed the manuscript critically.

\section{REFERENCES}

BAILEY, S.W. (1966). Clays and Clay Minerals, 14, 1.

Bailey, S.W. (1969). Clays and Clay Minerals, 17, 355.

Bailey, S.W. \& Brown, B.E. (1962). Amer. Min., 47, 819.

Bailey, S.W. \& Tyler, S.A. (1960). Ec. Geol., 55, 150.

Eggleton, R.A. \& Bailey, S.W. (1967). Amer. Min., 52, 673.

Fawcett, J.J. \& Yoder, H.S. (1966). Amer. Min., 51, 353.

Gillery, F.H. (1959). Amer. Min., 44, 143.

Hayashi, H. \& Oinuma, K. (1965). Amer. Min., 50, 476.

Nelson, B.W. \& RoY, R. (1958). Amer. Min., 43, 707.

Roy, D.M. \& Roy, R. (1955). Amer. Min., 40, 147.

Roy, R. (1956). Journ. Amer. Cer. Soc., 39, 145.

Segnit, E.R. (1963). Amer. Min., 48, 1080.

Serratosa, J.M. \& Vinas, J.M. (1964). Nature, 202, 999.

Shirozu, H. (1958). Min. Journ., 2, 209.

Shirozu, H, (1960). Mem. Fac. Sci., Kyushu Univ., D, 9, 183.

ShirozU, H. (1967). Journ. Miner. Soc. Japan., 8, 289.

Stubican, V. \& Roy, R. (1961). Amer. Min., 46, 32.

Tuddenham, W.M. \& Lyon, R.J.P. (1959). Anal. Chem., 31, 377.

YODER, H.S. (1952). Amer. Journ. Sci., Bowen vol., 569. 